\title{
Desempenho, frequência de diarreia, produção de fezes e custos de dietas com teores crescentes de farelo de abacaxi para leitões desmamados
}

\author{
[Performance, diarrhea frequency, feces production and costs of diets with increasing levels \\ of pineapple byproducts in weaned piglets] \\ G.F. Ramos ${ }^{1}$, C.D.S. Júnior ${ }^{1}$, J.A. Oliveira ${ }^{1}$, T.S. Vasconcelos ${ }^{1}$, F.E.L. Budiño ${ }^{2}$, U.S. Ruiz ${ }^{3 *}$ \\ ${ }^{1}$ Universidade Estadual Paulista - Dracena, SP \\ ${ }^{2}$ Instituto de Zootecnia - Nova Odessa, SP \\ ${ }^{3}$ Universidade de São Paulo - Piracicaba, SP
}

\begin{abstract}
RESUMO
Esta pesquisa objetivou avaliar dietas com teores crescentes de farelo de abacaxi na alimentação de leitões desmamados. Foram utilizados 56 leitões, no intervalo de 21 a 63 dias de idade, que receberam dietas compostas principalmente por milho, farelo de soja e produtos lácteos, com adição de farelo de abacaxi em $0 \%, 3,4 \%, 6,8 \%$ e 10,2\%. Foram avaliados o desempenho zootécnico; a incidência de diarreia; as excreções nas fezes, totais e por unidade de peso vivo ganho, de matérias seca (MS), mineral $(\mathrm{MM})$ e orgânica $(\mathrm{MO})$, nitrogênio $(\mathrm{N})$ e fósforo $(\mathrm{P})$; os custos relativos ao ganho de peso dos animais e os índices de eficiência econômica e de custo. As avaliações foram efetuadas dos 21 aos 35 dias; dos 21 aos 49 dias; e dos 21 aos 63 dias de idade dos leitões. Adotou-se delineamento em blocos ao acaso, de acordo com os pesos dos animais no início do experimento, com quatro tratamentos e sete repetições. Dos 21 aos 49 dias os animais submetidos às dietas com 3,4 e 6,8\% de farelo de abacaxi consumiram mais ração $(\mathrm{P}<0.05)$ do que os alimentados com a dieta controle, e dos 21 aos 63 dias verificou-se maior ganho de peso $(\mathrm{P}<0.05)$ somente dos animais que receberam a dieta com $3,4 \%$ de farelo de abacaxi em relação aos leitões controle. Dos 21 aos 63 dias os animais que receberam as dietas com farelo de abacaxi apresentaram excreções de MS, MM, MO e N superiores $(\mathrm{P}<0.05)$ às dos animais controle. Contudo, ao se verificarem as excreções destes componentes nas fezes por unidade de peso vivo ganho neste mesmo período, foi constatado que não houve diferença $(\mathrm{P}>0.05)$ entre os leitões que receberam as dietas sem farelo de abacaxi e os que consumiram a dieta com 3,4\% do produto. Portanto, a inclusão do farelo de abacaxi em dietas para leitões desmamados em 3,4\% é viável, por não interferir negativamente nas excreções por unidade de peso vivo ganho e nos índices de custos das dietas e por proporcionar melhor ganho de peso aos leitões em relação àqueles que não consumiram farelo de abacaxi.
\end{abstract}

Palavras-chave: excreção de resíduos, fibra dietética, ganho de peso

\begin{abstract}
This research aimed to evaluate diets with growing levels of pineapple meal in weaned piglets feeding. Fifty-six piglets, from 21 to 63 days old, were fed diets composed mainly of corn, soybean meal, and dairy products, with the addition of pineapple byproduct in $0 \%, 3.4 \%, 6.8 \%$ and $10.2 \%$. The parameters evaluated were: growth performance; diarrhea incidence; excretion in feces, total and per unit of weight gain, of dry (DM), mineral (MM) and organic (OM) matters, nitrogen (N) and phosphorous (P); diet costs related to weight gain, index of economic efficiency and of costs. The evaluations were performed from 21 to 35 days; from 21 to 49 days; and from 21 to 63 days of age. A complete randomized block design was adopted, according to the animal's weight in the beginning of the trial, with four treatments and seven repetitions. From day 21 to 49 the animals fed diets with 3.4 and 6.8\% of pineapple meal consumed more feed $(P<0.05)$ than those fed the control diet, and from day 21 to 63 only the animals that
\end{abstract}

Recebido em 3 de maio de 2015

Aceito em 12 de maio de 2016

* Autor para correspondência (corresponding author)

E-mail: usruiz@usp.br 
received the diet with $3.4 \%$ of pineapple presented a higher weight gain $(P<0.05)$ than control piglets. From day 21 to 63 animals fed diets with pineapple meal presented higher $(P<0.05)$ excretions of $D M$, $M M, O M$, and $N$ than the control animals. However, checking the excretions of these components in the feces per unit of live weight gain in the same period, it was found that there was no difference $(P>0.05)$ among the piglets fed diets without pineapple meal and those who consumed the diet with $3.4 \%$ of the product. Thus, the inclusion of pineapple meal in weaned piglet's diets at $3.4 \%$ is feasible, because it did not interfere negatively on excretions per unit of live weight gain and in diet cost indices, and provided better weight gain to the animals, as compared with pigs who did not consume pineapple meal.

Keywords: dietary fiber, excretion of residues, weight gain

\section{INTRODUÇÃO}

Especial atenção tem sido destinada à alimentação de leitões na fase pós-desmame, por se tratar do período mais crítico no sistema de produção de suínos (Corassa et al., 2007), o qual reúne diversos fatores que podem prejudicar o desenvolvimento dos leitões e causar prejuízo econômico ao produtor.

Algumas estratégias nutricionais/alimentares têm sido empregadas para minimizar os efeitos negativos do desmame, visando à manutenção da saúde intestinal, como a inclusão de antibióticos em doses subterapêuticas nas dietas de leitões, de modo a controlar microrganismos nocivos que possam causar diarreia, e/ou o uso de ingredientes altamente digestíveis, como derivados do leite. Porém, o uso de antibióticos promotores de crescimento tem sido restringido na produção animal, e os derivados do leite e outros ingredientes de origem animal apresentam custo elevado. Dessa maneira, torna-se importante a busca por novas tecnologias ou ingredientes alimentares capazes de contribuir para o funcionamento eficaz do trato gastrintestinal dos animais, favorecendo o bom desempenho (Pascoal et al., 2012) e atendendo aos padrões internacionais de segurança alimentar.

$\mathrm{O}$ emprego de ingredientes fibrosos nas dietas pós-desmame de leitões pode constituir interessante estratégia para melhorar a saúde intestinal desses animais, pela possível modulação da microbiota intestinal em favor do hospedeiro. A fração fibrosa dos ingredientes vegetais não é digerida enzimaticamente por suínos, tornando-se disponível à fermentação microbiana no intestino grosso (Molist et al., 2009) e, assim, gerando substratos benéficos aos animais, como os ácidos graxos de cadeia curta (AGCC).
Adicionalmente, há evidências de que fontes de fibra dietética insolúvel podem diminuir a ocorrência de problemas entéricos (Williams et al., 2001). Esse tipo de fibra modifica a motilidade gastrintestinal, prolongando a permanência da digesta no estômago e reduzindo no intestino, o que aumenta a atividade das enzimas pancreáticas e a produção de enzimas intestinais (Carneiro et al., 2008).

O farelo de abacaxi é um ingrediente fibroso, derivado da prensagem do fruto para a obtenção do suco, sendo considerado rejeito pela indústria. Consiste de 15 a $25 \%$ do peso do fruto, sendo composto por talos, coroas, cascas e cilindros. O Brasil é um dos maiores produtores mundiais, tendo produzido $3.133,381$ toneladas do fruto no ano de 2013, e a região Sudeste é responsável por $40,65 \%$ dessa produção, ou seja, equivalente a 1.273,585 toneladas (Agrianual, 2014). O farelo seco apresenta $87,11 \%$ de matéria seca, $93,81 \%$ de matéria orgânica, $7,70 \%$ de matéria mineral (Valadares et al., 2014), 67,50\% de fibra dietética total, $9,50 \%$ de fibra dietética solúvel, $58,00 \%$ de fibra dietética insolúvel (Vasconcelos, 2014), 80,21\% de carboidratos totais, $14,07 \%$ de carboidratos não fibrosos (Rogério et al., 2007) e 8,35\% de proteína bruta (Lousada Júnior et al., 2006).

Pela grande disponibilidade e variedade de subprodutos fibrosos que há no Brasil e pela necessidade de alimentos alternativos, que minimizem os problemas decorrentes do desmame, objetivou-se com este trabalho avaliar a inclusão do farelo de abacaxi, em teores crescentes nas dietas de leitões desmamados, sobre o desempenho zootécnico, a ocorrência de diarreia, de excreções de matérias seca, mineral e orgânica, nitrogênio e fósforo nas fezes, e a avaliação econômica das dietas. 


\section{MATERIAL E MÉTODOS}

Os procedimentos com animais foram revistos e aprovados pela Comissão de Ética em Uso de Animais da "Universidade Estadual Paulista", campus de Dracena (protocolo $n^{\circ} 31 / 2013$ ), e seguiram-se as normas estabelecidas pelo Conselho Nacional de Controle da Experimentação Animal (Concea). O experimento foi conduzido no galpão de creche do Instituto de Zootecnia de Nova Odessa (IZ). Foram utilizados 56 leitões recém-desmamados, machos e fêmeas, com 21 dias de idade e peso médio de $5,05 \pm 0,89 \mathrm{~kg}$, obtidos de granja comercial, onde foram previamente vacinados contra circovírus.

Os leitões foram alojados dois a dois, um macho e uma fêmea, em gaiolas metálicas suspensas a $80 \mathrm{~cm}$ do piso e localizadas em duas salas de creche, com pé direito de $3 \mathrm{~m}$, fechadas por todos os lados com paredes e janelas e dotadas de climatizadores que mantiveram a temperatura entre 25 e $28^{\circ} \mathrm{C}$, zona de conforto térmico de leitões. Os bebedouros utilizados foram do tipo chupeta e os comedouros do tipo semiautomático.

Foram empregadas quatro dietas experimentais. A dieta controle (CON) foi composta por milho, farelo de soja, produtos lácteos, plasma sanguíneo, suplementadas com minerais, vitaminas e aminoácidos (Tab. 1). Nas demais dietas incluíram-se $3,4 \%, 6,8 \%$ e $10,2 \%$ de farelo de abacaxi, sendo tais dietas denominadas A34, A68 e A102.

O programa de arraçoamento foi dividido em três fases: I, dos 21 aos 35 dias de vida dos animais; II, dos 36 aos 49 dias; III, dos 50 aos 63 dias. Para formulação das dietas, consideraram-se as exigências por nutrientes de leitões de alto potencial genético e de desempenho superior, bem como os valores nutricionais dos ingredientes (Rostagno et al., 2011), nas fases mencionadas. Todas as dietas continham os mesmos teores de energia metabolizável, lisina, metionina + cistina, treonina, triptofano e valina digestíveis, cálcio e fósforo disponível.
Os animais receberam ração e água à vontade durante todo o ensaio, e se efetuou pesagem da ração fornecida e das sobras, que foram recolhidas diariamente, para quantificação do consumo diário de ração (CDR) dos animais. Os animais foram pesados aos 21,35 e 63 dias de idade, para o cálculo do ganho de peso diário (GPD), e com os valores de CDR e GDP calculou-se a conversão alimentar (CA), obtida pela razão entre o CDR e o GDP dos animais.

Nos primeiros 14 dias do experimento, às oito e às 17 horas, foram verificados, por análise visual, os aspectos das fezes dos animais de acordo com os seguintes escores: 1 - fezes normais, 2 - fezes pastosas e 3 - fezes aquosas. Os escores 1 e 2 foram considerados fezes não diarreicas e o 3 diarreicas. Essas identificações foram realizadas sempre pelo mesmo observador. Do total dessas observações, foram feitas as porcentagens dos escores 3, obtendo-se, assim, a porcentagem de diarreia.

Foram estimadas as excreções (E) dos animais em matéria seca - MS (EMS), matéria mineral MM (EMM), matéria orgânica - MO (EMO), nitrogênio - $\mathrm{N}(\mathrm{EN})$ e fósforo - $\mathrm{P}(\mathrm{EP})$. Para tanto, no meio de cada uma das fases, substituiuse parte do ingrediente inerte das dietas por uma fonte de cinzas insolúveis em ácido (CIA), a Celite ${ }^{\circledR}$, em $1 \%$ da dieta. Os animais consumiram as dietas com CIA por seis dias consecutivos e do quarto ao sexto dias efetuou-se coleta de amostras de fezes e de ração. Nas amostras efetuaram-se as seguintes determinações: MS por secagem em estufa, primeiramente a $55^{\circ} \mathrm{C}$ por três dias e posteriormente a $105^{\circ}$ por 12 horas; MM pela queima das amostras em forno mufla, a $600^{\circ} \mathrm{C}$ por quatro horas; N pelo método de Kjeldahl; para a determinação de $\mathrm{P}$ as amostras de fezes e rações foram digeridas em solução de ácido clorídrico e o P determinado por colorimetria; CIA por meio da digestão das amostras em ácido clorídrico 4 normal, sob aquecimento, durante 45 minutos, filtragem do resíduo em papel-filtro quantitativo e, finalmente, incineração dos filtros e resíduos retidos, em forno mufla a $500^{\circ} \mathrm{C}$ por quatro horas, conforme método adaptado de Van Keulen e Young (1977). 
Tabela 1. Composição (\%) e valores calculados das dietas experimentais nas fases I ( 21 a 35 dias), II (36 a 49 dias) e III (50 a 63 dias)

\begin{tabular}{|c|c|c|c|c|c|c|c|c|c|c|c|c|}
\hline \multirow{2}{*}{ Ingredientes } & \multicolumn{4}{|l|}{ Fase I } & \multicolumn{4}{|l|}{ Fase II } & \multicolumn{4}{|l|}{ Fase III } \\
\hline & $\mathrm{CON}$ & A34 & A68 & $\mathrm{A} 102$ & $\mathrm{CON}$ & $\mathrm{A} 34$ & $\mathrm{~A} 68$ & $\mathrm{~A} 102$ & $\mathrm{CON}$ & A34 & A68 & $\mathrm{A} 102$ \\
\hline Milho comum & 39,255 & 35,400 & 31,586 & 27,772 & 48,176 & 44,701 & 41,301 & 37,701 & 63,135 & 59,968 & 56,567 & 52,517 \\
\hline Farelo de soja & 29,374 & 29,374 & 29,374 & 29,374 & 32,470 & 32,470 & 32,470 & 32,470 & 29,199 & 29,199 & 29,199 & 29,199 \\
\hline Produto lácteo $^{1}$ & 16,299 & 16,299 & 16,299 & 16,299 & 3,040 & 3,040 & 3,040 & 3,040 & - & - & - & - \\
\hline Produto lácteo ${ }^{2}$ & 4,195 & 4,195 & 4,195 & 4,195 & 8,614 & 8,614 & 8,614 & 8,614 & - & - & - & - \\
\hline Plasma sanguíneo & 3,954 & 4,454 & 4,854 & 5,430 & 2,000 & 2,250 & 2,500 & 2,750 & - & - & - & - \\
\hline Farelo de abacaxi & - & 3,447 & 6,801 & 10,334 & - & 3,426 & 6,835 & 10,255 & - & 3,400 & 6,800 & 10,265 \\
\hline Fosfato bicálcico & 1,584 & 1,580 & 1,578 & 1,572 & 1,607 & 1,607 & 1,607 & 1,609 & 1,600 & 1,608 & 1,616 & 1,628 \\
\hline Calcário & 0,792 & 0,778 & 0,764 & 0,752 & 0,811 & 0,796 & 0,780 & 0,764 & 0,760 & 0,742 & 0,723 & 0,702 \\
\hline Sal & - & - & - & - & 0,187 & 0,169 & 0,152 & 0,138 & 0,443 & 0,445 & 0,447 & 0,450 \\
\hline Inerte & 2,132 & 1,975 & 1,830 & 1,611 & 2,133 & 1,881 & 1,600 & 1,420 & 1,939 & 1,612 & 1,418 & 1,575 \\
\hline Supl. mineral ${ }^{3}$ & 0,100 & 0,100 & 0,100 & 0,100 & 0,100 & 0,100 & 0,100 & 0,100 & 0,100 & 0,100 & 0,100 & 0,100 \\
\hline Supl. vitamínico ${ }^{4}$ & 0,300 & 0,300 & 0,300 & 0,300 & 0,300 & 0,300 & 0,300 & 0,300 & 0,300 & 0,300 & 0,300 & 0,300 \\
\hline Óleo de soja & 1,346 & 1,487 & 1,653 & 1,754 & - & 0,092 & 0,154 & 0,298 & 2,075 & 2,146 & 2,307 & 2,714 \\
\hline L-lisina $\mathrm{HCl}, 78 \%$ & 0,316 & 0,285 & 0,263 & 0,226 & 0,307 & 0,296 & 0,284 & 0,274 & 0,290 & 0,298 & 0,307 & 0,318 \\
\hline L-treonina, 98\% & 0,102 & 0,091 & 0,084 & 0,070 & 0,103 & 0,102 & 0,101 & 0,100 & 0,077 & 0,087 & 0,097 & 0,108 \\
\hline DL-metionina, 99\% & 0,169 & 0,168 & 0,160 & 0,166 & 0,132 & 0,137 & 0,141 & 0,147 & 0,062 & 0,073 & 0,085 & 0,099 \\
\hline L-triptofano, $98 \%$ & 0,006 & 0,002 & - & - & - & - & - & - & - & 0,002 & 0,003 & 0,005 \\
\hline L-valina, $96,5 \%$ & 0,055 & 0,045 & 0,039 & 0,025 & - & - & - & - & - & - & - & - \\
\hline Antioxidante & 0,020 & 0,020 & 0,020 & 0,020 & 0,020 & 0,020 & 0,020 & 0,020 & 0,020 & 0,020 & 0,020 & 0,020 \\
\hline TOTAL & 100,0 & 100,0 & 100,0 & 100,0 & 100,0 & 100,0 & 100,0 & 100,0 & 100,0 & 100,0 & 100,0 & 100,0 \\
\hline \multicolumn{13}{|l|}{ Valores calculados } \\
\hline EM (kcal/kg) & 3400 & 3400 & 3400 & 3400 & 3375 & 3375 & 3375 & 3375 & 3230 & 3230 & 3230 & 3230 \\
\hline PB (\%) & 22,0 & 22,2 & 22,4 & 22,6 & 21,4 & 21,5 & 21,6 & 22,0 & 18,9 & 19,0 & 18,9 & 18,8 \\
\hline FDT $(\%)$ & 7,7 & 10,5 & 12,9 & 16,0 & 9,3 & 11,6 & 14,0 & 15,3 & 9,4 & 11,4 & 15,3 & 19,0 \\
\hline FDS $(\%)$ & 0,6 & 0,8 & 0,8 & 0,8 & 0,6 & 0,6 & 0,8 & 0,8 & 0,4 & 0,3 & 0,6 & 0,7 \\
\hline FDI $(\%)$ & 7,1 & 9,8 & 12,1 & 15,2 & 0,7 & 11,1 & 13,2 & 14,5 & 9,1 & 11,1 & 14,7 & 18,2 \\
\hline Fósforo dig. (\%) & 0,5 & 0,5 & 0,5 & 0,5 & 0,4 & 0,4 & 0,4 & 0,4 & 0 & 0,4 & 0,4 & 0,4 \\
\hline Cálcio (\%) & 0,9 & 0,9 & 0,9 & 0,9 & 0,8 & 0,8 & 0,8 & 0,8 & 0 & 0,8 & 0,8 & 0,8 \\
\hline Celulose (\%) & 2,4 & 3,1 & 3,9 & 4,6 & 2,7 & 3,5 & 4,2 & 5,0 & 2,8 & 3,6 & 4,3 & 5,1 \\
\hline Lisina dig. (\%) & 1,5 & 1,5 & 1,5 & 1,5 & 1,3 & 1,3 & 1,3 & 1,3 & 1,1 & 1,1 & 1,1 & 0,1 \\
\hline Met + Cist dig. $(\%)$ & 0,8 & 0,8 & 0,8 & 0,8 & 0,7 & 0,7 & 0,7 & 0,7 & 0,6 & 0,6 & 0,6 & 0,6 \\
\hline Treonina dig. (\%) & 0,9 & 0,9 & 0,9 & 0,9 & 0,8 & 0,8 & 0,8 & 0,8 & 0,7 & 0,7 & 0,7 & 0,7 \\
\hline Triptofano dig. (\%) & 0,3 & 0,3 & 0,3 & 0,3 & 0,2 & 0,2 & 0,2 & 0,2 & 0,2 & 0,2 & 0,2 & 0,2 \\
\hline Valina dig. (\%) & 1,0 & 1,0 & 1,0 & 1,0 & 0,9 & 0,9 & 0,9 & 0,9 & 0,8 & 0,8 & 0,8 & 0,8 \\
\hline
\end{tabular}

CON- dieta controle; A34- 3,4\% de farelo de abacaxi; A68 - 6,8\% de farelo de abacaxi; A102-10,2\% de farelo de abacaxi. ${ }^{1}$ Nuklospray L70-5 - 70\% de lactose; ${ }^{2}$ Nuklospray E50 - 38\% de lactose; ${ }^{3}$ suplemento de microminerais (sem promotor do crescimento), fornecido por quilograma de dieta: cobalto $-0,168 \mathrm{mg}$; cobre $-0,015 \mathrm{~g}$; ferro $0,025 \mathrm{~g}$; iodo $-1,42 \mathrm{mg}$; manganês $-0,04 \mathrm{~g}$; zinco $-0,075 \mathrm{~g}$; ${ }^{4}$ suplemento vitamínico (sem promotor do crescimento): V=vit. A - 8000UI; vit. D3 - 3000UI; vit. K - 8mg; vit. B2 - 6mg; vit. B12 - 33mcg; vit. B6 - 2mg; vit. B1 - 2mg; vit. E - 30UI; pantotenato de cálcio $-21 \mathrm{mg}$; niacina $-0.04 \mathrm{~g}$; ácido fólico $-1.20 \mathrm{mg}$; biotina $-0.05 \mathrm{mg}$; selênio $0.39 \mathrm{mg}$; colina $-0.36 \mathrm{~g}$.

Com os teores de CIA nas amostras, foi possível determinar o fator de indigestibilidade (FI) das dietas, pela divisão do teor de CIA de cada dieta pelo teor de CIA das fezes de cada animal que as consumiu. $\mathrm{O}$ FI indica a porção da dieta não aproveitada pelos animais e excretada nas fezes.
Considerando-se os consumos das dietas pelos animais e o FI, foram calculadas as excreções de fezes, em base seca, de acordo com a seguinte fórmula, adaptada de (Berchielliet al., 2005):

\section{Excreção de MS fecal $(\mathrm{g})=$ Consumo de MS $\times$ FI}


Desempenho, frequência...

As excreções de MO, MM, N e P foram obtidas utilizando-se a seguinte fórmula:

Excreçåo de residuos $(\mathrm{g})=\frac{\text { Excreção de MS fecal } \times \text { Componentes das fezes }}{100}$

em que:

componentes das fezes $=\mathrm{MM}$ ou $\mathrm{MO}$ ou $\mathrm{N}$ ou $\mathrm{P}$, expressos como porcentagem das fezes na MS. Com base nesses dados, foram calculadas a produção média de fezes e as excreções médias de $\mathrm{MM}, \mathrm{MO}, \mathrm{N}$ e $\mathrm{P}$ dos animais por dieta experimental, em cada uma das fases.

Por fim, foram calculadas as excreções de MS, $\mathrm{MM}, \mathrm{MO}, \mathrm{N}$ e $\mathrm{P}$ nas fezes dos suínos por unidade de peso vivo ganho (EXCPV), em cada uma das fases experimentais, de acordo com a seguinte fórmula, adaptada de Santos (2001):

\section{Excreçto por unidade de pero vivo ganho $=\frac{M S \text { ou } M M \text { ou } M O \text { ou } \mathrm{N} \text { ou } \mathrm{P} \text { eliminado nas fezes }(\mathrm{g})}{\text { Quantidade total de peso vivo produzido }(\mathrm{kg})}$}

Primeiramente foi calculado o custo médio da ração por quilograma de peso vivo ganho (CMei) durante o período experimental, segundo a seguinte equação descrita por Bellaver et al. (1985):

$\mathrm{CMei}=\frac{\mathrm{Qi} \times \mathrm{Pi}}{\mathrm{Gi}}$

em que:

$\mathrm{CMe}_{\mathrm{i}}=$ custo médio da dieta por quilograma ganho no i-ésimo tratamento;

IEE $=\frac{\text { Mce }}{\text { Ctei }} \times 100$

em que:

Mce $=$ menor custo médio observado em dieta por quilograma de peso vivo ganho entre os tratamentos;

Ctei $=$ custo médio do tratamento i considerado.

Vale destacar que os custos dos ingredientes corresponderam aos valores pagos pelos produtos que compuseram as dietas, no estado de São Paulo, antes da realização do experimento (março de 2014).

Adotou-se o delineamento em blocos ao acaso, em função do peso vivo inicial dos animais. $\mathrm{Na}$ fase 1, a unidade experimental foi composta por dois animais, um macho castrado e uma fêmea, totalizando 56 animais, quatro dietas experimentais e sete repetições por dieta. Nas fases 2 e 3, a unidade experimental foi composta
Qi $=$ quantidade de dieta utilizada no i-ésimo tratamento;

$\mathrm{Pi}=$ preço médio por quilograma da dieta utilizada no i-ésimo tratamento;

$\mathrm{Gi}=$ ganho médio de peso do animal no i-ésimo tratamento.

Foram também determinados os índices de eficiência econômica (IEE) e de custo médio (IC), propostos por Barbosa et al. (1992):<smiles>[Mg][Mg][Te]</smiles>

por um animal, macho castrado, totalizando 28 animais, quatro dietas experimentais e sete repetições por dieta. Os dados foram submetidos à análise de variância, utilizando-se o procedimento GLM (General Linear Models) do programa estatístico SAS (Statistical Analysis System, 2008), e os resultados médios foram submetidos à análise de regressão e ao teste de Dunnett $(5 \%)$ para análise das médias. A normalidade dos erros foi testada pelo método de Cramer-von Mises, de acordo com Everitt (1998). Para a variável ocorrência de diarreia, os dados passaram por transformação angular. Com exceção da ocorrência de diarreia, todos os demais cálculos foram efetuados nos períodos acumulados de 21-35 (período I), 21-49 (período II) e 21-63 dias de idade (período III), visto que não houve redistribuição dos animais nos blocos ao final de cada fase. 


\section{RESULTADOS E DISCUSSÃO}

Para todas as variáveis de desempenho e para as de ocorrência de diarreia no período I, para o ganho de peso diário e a conversão alimentar no período II e para consumo de ração diário e a conversão alimentar no período III, não foram observadas diferenças $(\mathrm{P}>0,05)$ entre os animais submetidos às diferentes dietas experimentais (Tab. 2). Tais resultados estão de acordo com os encontrados por Pascoal et al. (2012), que utilizaram casca de soja, polpa cítrica e celulose purificada em dietas para leitões e concluíram que a utilização desses produtos não afetou $o$ desempenho produtivo dos animais.

O consumo de ração diário no período II aumentou $(P<0,05)$ linearmente em função do aumento da inclusão de farelo de abacaxi nas dietas dos animais. No período total, observou-se efeito quadrático $(\mathrm{P}<0,05)$ sobre o ganho de peso diário dos suínos, sendo o nível ótimo estimado de inclusão de 7,43\% de farelo de abacaxi (Tab. $3)$.

Ao se compararem os desempenhos dos leitões submetidos às dietas com farelo de abacaxi separadamente com os dos animais alimentados com a dieta controle, verificou-se que os consumos de ração dos animais A34 e dos A102 foram superiores $(\mathrm{P}<0,05)$ aos do controle no período II e que o ganho de peso dos animais A34 foi $40 \%$ maior $(\mathrm{P}<0.05)$ do que o dos animais controle no período III.

Tabela 2. Desempenho e ocorrência de diarreia de leitões alimentados com dietas com teores crescentes de farelo de abacaxi nos períodos I ( 21 - 35 dias de idade), II (21 - 49 dias de idade) e III (21 - 63 dias de idade)

\begin{tabular}{|c|c|c|c|c|c|c|c|c|}
\hline \multirow{2}{*}{ Variáveis } & \multirow{2}{*}{ Período } & \multicolumn{4}{|l|}{ Dietas } & \multirow{2}{*}{$-\mathrm{CV}(\%)$} & \multirow{2}{*}{ Efeito } & \multirow{2}{*}{$\mathrm{P}$} \\
\hline & & $\mathrm{CON}$ & A34 & A68 & A102 & & & \\
\hline \multirow{3}{*}{ Ganho de peso diário, $\mathrm{g}$} & I & 220 & 221 & 243 & 231 & 20,9 & - & 0,8666 \\
\hline & II & 302 & 374 & 344 & 353 & 23,3 & - & 0,4627 \\
\hline & III & 339 & $509 *$ & 470 & 421 & 24,3 & Quadrático & 0,0133 \\
\hline \multirow{3}{*}{ Consumo de ração diário, $\mathrm{g}$} & I & 289 & 306 & 310 & 359 & 24,8 & - & 0,4102 \\
\hline & II & 390 & $546^{*}$ & 475 & $562 *$ & 27,8 & Linear & 0,0301 \\
\hline & III & 607 & 787 & 711 & 785 & 27,9 & - & 0,133 \\
\hline \multirow{3}{*}{ Conversão alimentar } & I & 1,4 & 1,4 & 1,4 & 1,5 & 19,5 & - & 0,3517 \\
\hline & II & 1,6 & 1,6 & 1,4 & 1,6 & 15,7 & - & 0,5106 \\
\hline & III & 1,9 & 1,6 & 1,6 & 1,9 & 13,4 & - & 0,21 \\
\hline \multicolumn{9}{|l|}{ Ocorrência de diarreia } \\
\hline$\%$ de escore 3 & 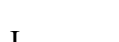 & 28,99 & 25,05 & 24,35 & 16,78 & 71,5 & - & - \\
\hline Médias transformadas & 1 & 0,522 & 0,512 & 0,503 & 0,397 & & - & 0,3900 \\
\hline
\end{tabular}

*Diferente em relação ao controle pelo teste de Dunnett (5\%).

CON- dieta controle; A34 - 3,4\% de farelo de abacaxi; A68 - 6,8\% de farelo de abacaxi; A102 - 10,2\% de farelo de abacaxi.

Tabela 3. Equações de predição dos resultados de desempenho de leitões alimentados com dietas com teores crescentes de resíduo de abacaxi

\begin{tabular}{llll}
\hline Variáveis & Equação & $\mathrm{R}^{2}$ & Nível ótimo \\
\hline Consumo de ração diário & $0,0191 \mathrm{x}+0,3556$ & 0,1979 & - \\
Ganho de peso diário & $-0,0043 \mathrm{x}^{2}+0,0639 \mathrm{x}+0,3041$ & 0,2948 & 7,43 \\
\hline
\end{tabular}

Os maiores consumo de ração e ganho de peso dos animais submetidos à dieta A34 em relação aos leitões controle podem estar relacionados ao fato de que fontes de fibra insolúvel, como o farelo de abacaxi, quando em pequenas quantidades, atuam positivamente regulando ou estimulando o consumo de ração (Hetland et al., 2004), além de poderem acelerar o tempo de trânsito gastrintestinal e, dessa forma, reduzir a atividade de microrganismos patogênicos (Smits e Annison, 1996). Tais pontos foram confirmados por Han et al. (2005), que, ao testarem quatro concentrações $(0 ; 0,3 ; 0,6$; e $0,9 \%$ ) de inclusão de uma fonte purificada de fibra insolúvel (Vitacel $\AA$ ) em dietas para leitões desmamados, concluíram que o teor de $0,3 \%$ melhorou o desempenho produtivo. 
No entanto, na literatura, o desempenho de leitões alimentados com dietas fibrosas mostra-se variável. Schiavon et al. (2004) testaram a inclusão de $12 \%$ de polpa de beterraba nas dietas para leitões desmamados e não observaram efeito da adição dessa fonte de fibra sobre o CDR e a CA, porém observaram pior ganho de peso nos animais alimentados com maior inclusão de fibra na dieta.

De forma diferente, Molist et al. (2009) avaliaram rações contendo farelo de trigo e polpa de beterraba, juntas ou separadamente, e dietas sem as fibras para leitões recém-desmamados. Os autores notaram que, nos primeiros 10 dias pós-desmame, os animais que receberam farelo de trigo apresentaram maior consumo de ração quando comparados aos que não ingeriram essa fibra, porém não notaram diferença para ganho de peso e conversão alimentar.

Apenas as excreções de $\mathrm{P}$ no período III não foram afetadas $(\mathrm{P}>0,05)$ pela inclusão de farelo de abacaxi nas rações (Tab. 4). Para as excreções de MS, MM, MO, $\mathrm{N}$ e $\mathrm{P}$ no período I, e de MM no período II, verificou-se efeito quadrático $(\mathrm{P}<0,05)$. Para as excreções de MS, MO e $\mathrm{N}$ nos períodos II e III, de MM no período III e de P no período II, verificaram-se aumentos lineares $(\mathrm{P}<0,05)$ em razão do incremento do farelo de abacaxi às dietas dos animais.

De maneira geral, verificou-se que o aumento do farelo de abacaxi nas dietas ocasionou aumentos nas excreções, sobretudo para os animais que receberam a dieta com maior porcentagem de fibra. Isso se deve ao fato de que a fibra, além de não ser digerida pelas enzimas produzidas por suínos, pode afetar negativamente a digestão de outros componentes da dieta, levando ao aumento na excreção de fezes. Ao se fazerem as comparações dos animais controle em relação aos demais grupos de animais, observou-se o seguinte: todos os grupos de animais que receberam farelos de abacaxi em suas dietas apresentaram excreções de MS, MO e N maiores $(\mathrm{P}<0,05)$ que as dos animais controle no período III; para MM no período III, MO, N e P no período II, apenas os leitões que receberam as dietas A34 e A102 apresentaram aumentos $(\mathrm{P}<0,05)$ nas excreções em relação aos animais controle; no período II, apenas os animais submetidos à dieta $\mathrm{A} 102$ aumentaram $(\mathrm{P}<0,05)$ a excreção de MS em relação aos suínos que não receberam farelo de abacaxi.

Tabela 4. Excreções totais de matérias seca, mineral e orgânica, nitrogênio e fósforo nas fezes de leitões desmamados, alimentados com dietas com teores crescentes de farelo de abacaxi nos períodos I (21 - 35 dias de idade) e II (21 - 49 dias de idade) e III (21 - 63 dias de idade)

\begin{tabular}{|c|c|c|c|c|c|c|c|c|}
\hline \multirow{2}{*}{ Variáveis } & \multirow{2}{*}{ Período } & \multicolumn{4}{|l|}{ Dietas } & \multirow{2}{*}{$-\mathrm{CV}(\%)$} & \multirow{2}{*}{ Efeito } & \multirow{2}{*}{$\mathrm{P}$} \\
\hline & & $\mathrm{CON}$ & A34 & A68 & A102 & & & \\
\hline \multicolumn{9}{|l|}{ Excreções, g } \\
\hline \multirow{3}{*}{ Matéria seca } & I & 520,8 & 656,3 & 611,1 & $2020,6^{*}$ & 32,0 & Quadrático & $<0,0001$ \\
\hline & II & 1474,0 & 2467,8 & 2055,7 & $4107,8^{*}$ & 27,7 & Linear & $<0,0001$ \\
\hline & III & 3184,3 & $6092,9 *$ & $5254,6^{*}$ & $7254,6^{*}$ & 26,2 & Linear & $<0,0001$ \\
\hline \multirow{3}{*}{ Matéria mineral } & I & 133,7 & 147,0 & 128,4 & $383,8 *$ & 33,2 & Quadrático & $<0,0001$ \\
\hline & II & 354,0 & 467,8 & 362,9 & $723,8^{*}$ & 24,7 & Quadrático & 0,0102 \\
\hline & III & 719,2 & $1065,0 *$ & 860,2 & $1202,9 *$ & 22,7 & Linear & 0,0024 \\
\hline & I & 387,0 & 509,3 & 482,8 & $1636,8 *$ & 32,6 & Quadrático & $<0,0001$ \\
\hline \multirow[t]{3}{*}{ Matéria orgânica } & II & 1120,1 & $2000,1 *$ & 1692,7 & $3384,1 *$ & 29,3 & Linear & $<0,0001$ \\
\hline & III & 2465,1 & $5027,9 *$ & $4394,4 *$ & $6051,9 *$ & 27,7 & Linear & $<0,0001$ \\
\hline & I & 23,7 & 28,4 & 25,4 & $82,6^{*}$ & 33,8 & Quadrático & $<0,0001$ \\
\hline \multirow[t]{3}{*}{ Nitrogênio } & II & 66,0 & $108,6^{*}$ & 83,0 & $165,2^{*}$ & 29,2 & Linear & $<0,0001$ \\
\hline & III & 149,7 & $277,0^{*}$ & $207,7^{*}$ & $280,4^{*}$ & 24,5 & Linear & 0,0022 \\
\hline & I & 5,6 & 5,7 & 5,0 & $14,1 *$ & 42,7 & Quadrático & 0,0013 \\
\hline \multirow[t]{2}{*}{ Fósforo } & II & 15,7 & $23,7^{*}$ & 17,7 & $30,0 *$ & 32,1 & Linear & 0,0045 \\
\hline & III & 45,9 & 57,2 & 42,8 & 55,4 & 21,6 & - & $>0,20$ \\
\hline
\end{tabular}

*Diferente em relação ao controle pelo teste de Dunnett (5\%).

CON- dieta controle; A34- 3,4\% de farelo de abacaxi; A68- 6,8\% de farelo de abacaxi; A102- 10,2\% de farelo de abacaxi. 
Tabela 5. Equações de predição das excreções de nutrientes de leitões alimentados com dietas com teores crescentes de resíduo de abacaxi

\begin{tabular}{llllc}
\hline Variáveis & Período & Equações & $\mathrm{R}^{2}$ & Nível ótimo \\
\hline Excreções, g & & & & \\
\hline \multirow{2}{*}{ Matéria seca } & I & $26,828 \mathrm{x}^{2}-146,06 \mathrm{x}+601,58$ & 0,8123 & 2,7 \\
& II & $219,11 \mathrm{x}+1403,4$ & 0,5851 & - \\
\multirow{4}{*}{ Matéria mineral } & III & $331,69 \mathrm{x}+3746,6$ & 0,4637 & - \\
& I & $5,1048 \mathrm{x}^{2}-31,167 \mathrm{x}+148,77$ & 0,7324 & 3,1 \\
\multirow{2}{*}{ Matéria orgânica } & II & $5,2273 \mathrm{x}^{2}-24,447 \mathrm{x}+388,22$ & 0,5746 & 2,3 \\
& III & $36,423 \mathrm{x}+775,13$ & 0,3142 & - \\
\multirow{2}{*}{ Nitrogênio } & I & $21,72 \mathrm{x}^{2}-114,85 \mathrm{x}+452,67$ & 0,8199 & - \\
& II & $189,67 \mathrm{x}+1077,2$ & 0,5959 & - \\
Fósforo & I & $295,27 \mathrm{x}+2971,5$ & 0,4738 & 2,9 \\
& II & $1,1066 \mathrm{x}^{2}-6,3218 \mathrm{x}+27,067$ & 0,7743 & - \\
\hline
\end{tabular}

$\mathrm{O}$ aumento de fibra nas dietas proporcionou aumento linear $(\mathrm{P}<0,05)$ no consumo de ração $(\mathrm{P}<0,05)$ no período II, o que também contribuiu para as maiores excreções. Moreira et al. (2007), ao avaliarem restrição energética para suínos por meio de elevação no teor de fibra das dietas, observaram aumento nas excreções de MS e MO, porém não verificaram efeito sobre as excreções de $\mathrm{N}$ e $\mathrm{P}$.

De modo semelhante, Fraga et al. (2009), ao fornecerem níveis crescentes de casca de arroz em substituição ao milho para suínos em terminação, obtiveram maiores excreções de sólidos voláteis e totais, além de redução nas excreções de nitrogênio e fósforo. Castelini (2011), ao utilizar casca de soja em teores crescentes para suínos, também observou aumento nas excreções de sólidos totais, sólidos voláteis e matéria mineral, porém encontrou redução nas excreções de nitrogênio e fósforo.

Nos períodos I e II, todas as excreções de componentes das fezes por unidade de peso vivo ganho (EXCPV) apresentaram efeito quadrático $(\mathrm{P}<0,05)$, assim como as EXCPV de MM e P no período III (Tab. 6). Os níveis de farelo de abacaxi estimados que promoveriam as menores EXCPV encontram-se na Tab. 7. De forma diferente, as EXCPV de MS, MO e N no período III apresentaram aumentos lineares $(\mathrm{P}<0,05) \mathrm{em}$ decorrência do incremento nos teores de farelo de abacaxi às dietas. Esses resultados podem estar relacionados à piora no aproveitamento das dietas, relacionada à baixa capacidade de digerir fibras, principalmente em leitões, e ao aumento numérico do consumo de ração no período total em função dos maiores teores fibra nas dietas dos animais. Tais aspectos podem ter provocado as maiores excreções totais, vistas anteriormente, que culminaram nos maiores excreções por unidade de peso ganho conforme aumentaram os teores de farelo de abacaxi nas dietas.

As EXCPV de MS no período I, MO e $\mathrm{N}$ nos períodos I e III, P nos períodos I e II e MM em todos os períodos, dos animais alimentados com a dieta $\mathrm{A} 102$, foram maiores $(\mathrm{P}<0,05)$ em relação aos que consumiram a dieta controle. Para as EXCPV da MS, MO e $\mathrm{N}$ no período II, os animais alimentados com as dietas A34 e A102 diferiram dos animais do grupo controle, assim como para a EXCPV do P no período III, dos animais alimentados com as dietas A34 e A68 (Tab. 6).

Contudo, é importante observar que, no período total, não houve diferenças $(\mathrm{P}>0,05)$ nas EXCPV da MS, MM, MO e do $\mathrm{N}$ entre os animais do tratamento $\mathrm{CON}$ e os que receberam a dieta A34. Ou seja, o aumento na excreção de resíduos dos animais A34 foi acompanhado por maior ganho de peso, de modo que as excreções por unidade de peso ganho não diferiram.

Não houve diferença $(\mathrm{P}>0,05)$ para $\mathrm{o}$ custo médio das rações por quilograma de peso vivo entre as dietas em nenhum dos períodos (Tab. 8). Contudo, a dieta A68 apresentou os melhores IEE e IC, indicando, assim, a viabilidade econômica da inclusão do farelo de abacaxi, sem afetar a eficiência econômica e os custos das dietas. 
Tabela 6. Excreções de matérias seca, mineral e orgânica, nitrogênio e fósforo nas fezes por unidade de peso vivo ganho (EXCPV) de leitões desmamados, alimentados com teores crescentes de farelo de abacaxi nos períodos I ( 21 - 35 dias de idade), II (21 - 49 dias de idade) e III (21 - 63 dias de idade)

\begin{tabular}{|c|c|c|c|c|c|c|c|c|}
\hline \multirow[b]{2}{*}{ Variáveis } & \multirow[b]{2}{*}{ Período } & \multicolumn{4}{|l|}{ Dietas } & \multirow{2}{*}{$-C V(\%)$} & \multirow{2}{*}{ Efeito } & \multirow[b]{2}{*}{$\mathrm{P}$} \\
\hline & & $\overline{\mathrm{CON}}$ & A34 & A68 & A102 & & & \\
\hline \multicolumn{9}{|l|}{ EXCPV, g/kg } \\
\hline \multirow{3}{*}{ Matéria seca } & I & 148,6 & 195,6 & 172,7 & $602,0^{*}$ & 36,9 & Quadrático & $<0,0001$ \\
\hline & II & 173,2 & $229,5^{*}$ & 204,1 & $408,3 *$ & 22,2 & Quadrático & 0,0019 \\
\hline & III & 220,9 & 247,2 & 244,6 & 390,8 & 29,4 & Linear & 0,0011 \\
\hline & I & 38,7 & 44,3 & 36,5 & $115,0^{*}$ & 39,4 & Quadrático & 0,0003 \\
\hline \multirow[t]{3}{*}{ Matéria mineral } & II & 40,8 & 43,9 & 35,7 & $72,5^{*}$ & 22,0 & Quadrático & 0,0003 \\
\hline & III & 48,4 & 42,9 & 40,2 & $65,0^{*}$ & 27,1 & Quadrático & 0,0058 \\
\hline & I & 110,5 & 151,4 & 136,2 & $487,0^{*}$ & 37,0 & Quadrático & $<0,0001$ \\
\hline \multirow[t]{3}{*}{ Matéria orgânica } & II & 132,4 & $185,6^{*}$ & 168,4 & $335,8^{*}$ & 23,4 & Quadrático & 0,0043 \\
\hline & III & 172,6 & 204,3 & 204,5 & $325,8^{*}$ & 30,6 & Linear & 0,0006 \\
\hline & I & 6,8 & 8,4 & 7,2 & $24,8^{*}$ & 39,0 & Quadrático & 0,0001 \\
\hline \multirow{3}{*}{ Nitrogênio } & II & 7,6 & $10,0^{*}$ & 8,3 & $16,5^{*}$ & 24,6 & Quadrático & 0,0075 \\
\hline & III & 9,1 & 11,2 & 9,4 & $14,4^{*}$ & 20,5 & Linear & 0,0012 \\
\hline & I & 1,6 & 1,7 & 1,5 & $4,1^{*}$ & 39,7 & Quadrático & 0,0014 \\
\hline \multirow[t]{2}{*}{ Fósforo } & II & 1,8 & 2,2 & 1,8 & $3,0^{*}$ & 24,2 & Quadrático & 0,04 \\
\hline & III & 2,9 & $2,3^{*}$ & $2,0^{*}$ & 2,8 & 21,9 & Quadrático & 0,0015 \\
\hline
\end{tabular}

*Diferente em relação ao controle pelo teste de Dunnett (5\%).

CON - dieta controle; A34 - 3,4\% de farelo de abacaxi; A68 - 6,8\% de farelo de abacaxi; A102 - 10,2\% de farelo de abacaxi.

Tabela 7. Equações de predição das excreções de matérias seca, mineral e orgânica, de nitrogênio e fósforo nas fezes por unidade de peso vivo ganho (EXCPV) de leitões alimentados com dietas de teores crescentes de resíduo de abacaxi

\begin{tabular}{lllll}
\hline Variáveis & Período & Equações & $\mathrm{R}^{2}$ & Nível ótimo \\
\hline EXCPV, g/kg & & & & \\
\hline \multirow{2}{*}{ Matéria seca } & I & $8,0525 \mathrm{x}^{2}-43,829 \mathrm{x}+174,41$ & 0,7719 & 2,72 \\
& II & $3,1174 \mathrm{x}^{2}-12,226 \mathrm{x}+188,68$ & 0,7208 & 1,96 \\
& III & $14,854 \mathrm{x}+199,77$ & 0,3246 & - \\
Matéria mineral & I & $1,5388 \mathrm{x}^{2}-9,3828 \mathrm{x}+43,632$ & 0,6688 & 3,05 \\
& II & $0,7136 \mathrm{x}^{2}-4,8008 \mathrm{x}+43,579$ & 0,6286 & 3,36 \\
& III & $0,6401 \mathrm{x}^{2}-5,2091 \mathrm{x}+49,581$ & 0,3525 & \\
Matéria orgânica & I & $6,5258 \mathrm{x}^{2}-34,621 \mathrm{x}+131,32$ & 0,7865 & 2,65 \\
& II & $2,4038 \mathrm{x}^{2}-7,4254 \mathrm{x}+145,1$ & 0,7193 & 1,54 \\
\multirow{2}{*}{ Nitrogênio } & III & $13,463 \mathrm{x}+157,78$ & 0,3586 & - \\
& I & $0,3348 \mathrm{x}^{2}-1,905 \mathrm{x}+7,8384$ & 0,7316 & 2,84 \\
& II & $0,1206 \mathrm{x}^{2}-0,5115 \mathrm{x}+8,2679$ & 0,6246 & 2,12 \\
Fósforo & III & $\mathrm{y}=0,4113 \mathrm{x}+8,9224$ & 0,329 & - \\
& I & $0,0508 \mathrm{x}^{2}-0,3105 \mathrm{x}+1,7365$ & 0,5978 & 3,06 \\
& II & $0,0175 \mathrm{x}^{2}-0,0955 \mathrm{x}+1,9632$ & 0,3749 & 2,73 \\
\hline
\end{tabular}

Gomes et al. (2012), ao avaliarem a viabilidade econômica de dietas com diferentes teores de farelo de arroz integral (FAI) em rações para leitões, concluíram que o FAI pode ser utilizado até o teor de $20 \%$ para leitões, sem que haja comprometimento nos índices de viabilidade econômica. 
Tabela 8. Custo médio de ração por quilograma de peso vivo (CMRPV), índice de eficiência econômica (IEE) e índice de custo de dietas para leitões desmamados, com teores crescentes de inclusão de farelo de abacaxi nos períodos I (dos 21 aos 35 dias de idade), II (dos 21 aos 49 dias de idade) e III (dos 21 aos 63 dias de idade)

\begin{tabular}{|c|c|c|c|c|c|c|c|}
\hline \multirow{2}{*}{ Variáveis } & \multirow{2}{*}{ Período } & \multicolumn{4}{|l|}{ Dietas } & \multirow{2}{*}{$\begin{array}{l}\mathrm{CV} \\
(\%)\end{array}$} & \multirow{2}{*}{$\mathrm{P}$} \\
\hline & & $\mathrm{CON}$ & A34 & A68 & A102 & & \\
\hline \multirow{3}{*}{$\begin{array}{l}\text { CMRPV, } \\
\mathrm{R} \$ / \mathrm{kg}\end{array}$} & I & 4,4 & 4,8 & 4,1 & 4,4 & 21,1 & 0,57 \\
\hline & II & 3,9 & 3,7 & 3,7 & 4,1 & 12,3 & 0,46 \\
\hline & III & 4,0 & 3,6 & 3,5 & 4,2 & 19,9 & 0,37 \\
\hline \multirow{3}{*}{ IEE, \% } & $\mathrm{I}$ & 93,2 & 85,4 & 100,0 & 93,2 & - & - \\
\hline & II & 94,9 & 100,0 & 100,0 & 90,2 & - & - \\
\hline & III & 87,5 & 97,2 & 100,0 & 83,3 & - & - \\
\hline \multirow{3}{*}{$\mathrm{IC}, \%$} & I & 107,3 & 117,1 & 100,0 & 107,3 & - & - \\
\hline & II & 105,4 & 100,0 & 100,0 & 110,8 & - & - \\
\hline & III & 114,3 & 102,9 & 100,0 & 120,0 & - & - \\
\hline
\end{tabular}

*Diferente em relação ao controle pelo teste de Dunnett (5\%).

CON - dieta controle; A34 - 3,4\% de farelo de abacaxi; A68 - 6,8\% de farelo de abacaxi; A102 - 10,2\% de farelo de abacaxi.

\section{CONCLUSÃO}

A inclusão do farelo de abacaxi em dietas para leitões desmamados é viável, sobretudo ao nível de $3,4 \%$, por não interferir negativamente nas excreções por unidade de peso vivo ganho e nos índices de custos das dietas e por proporcionar melhor ganho de peso aos animais em relação aos suínos que não consumiram farelo de abacaxi.

\section{REFERÊNCIAS}

AGRIANUAL 2014: anuário da agricultura brasileira. São Paulo: Informa Economics FNP, 2014. 463p.

BARBOSA, H.P.; FIALHO, E.T.; FERREIRA, A.S. et al. Triguilho para suínos nas fases inicial, de crescimento, crescimento e terminação. Rev. Bras. Zootec., v.21, p.827-37, 1992.

BELLAVER, C.; FIALHO, E.T.; PROTAS, J.F.S.; GOMES, P.C. Radícula de malte na alimentação de suínos em crescimento e terminação. Pesqui. Agropecu. Bras., v.20, p.969-974, 1985.

BERCHIELLI, T.T.; OLIVEIRA, S.G.; CARRILHO, E.N.V.M. et al. Comparação de indicadores para estimativas de produção fecal e de fluxo de digesta em bovinos. Rev. Bras. Zootec., v.34, p.987-996, 2005.
CARNEIRO, M.S.C.; LORDELLO, M.M.; CUNHA, L.F.; FREIRE, J.P.B. Effects of dietary fiber source and enzyme supplementation on fecal apparent digestibility, short chain fatty acid production and activity of bacterial enzymes in the gut of piglet. Anim. Feed Sci. Technol., v.146, p.124-136, 2008.

CASTELINI, F.R. Casca de soja em programa de restrição alimentar para suínos pesados. 2011. 82f. Dissertação (Mestrado em Zootecnia) - Faculdade de Ciências Agrárias e Veterinárias, Universidade Estadual Paulista, Jaboticabal, SP.

CORASSA, A.; LOPES, D.C.; PENA, S.M. et al. Hidrolisado de mucosa intestinal de suínos em substituição ao plasma sanguíneo em dietas para leitões de 21 a 49 dias. Rev. Bras. Zootec., v.36, p.2029-2036, 2007.

EVERITT, B.S. Cambridge dictionary of statistics. Cambridge: Cambridge University Press, 1998. 360p.

FRAGA, A.L.; THOMAZ, M.C.; KRONKA, R.N. et al. Qualitative feed restriction for heavy swines: effect on digestibility and weight of organs of digestive tract, and environmental impact of feces. Arq. Bras. Med. Vet. Zootec., v.61, p.1353-1363, 2009.

GOMES, T.R.; CARVALHO, L.E.; FREITAS, E.R. et al. Efeito da inclusão de farelo de arroz integral em rações para leitões de 21 a 42 dias de idade. Arq. Bras. Med. Vet. Zootec., v.61, p.129139, 2012. 
HAN, Y.K; HAN, K.Y.; LEE, J.H. Effects of insoluble dietary fiber supplementation on the performance and digestibility of weanling pigs. J. Anim. Sci. Technol., v.47, p.565-572, 2005.

HETLAND, H.; CHOCT, M.; SVIHUS, B. Role of insoluble non-starch polyssacharides in poultry nutrition. World Poult. Sci. J., v.60, p.415-422, 2004

LOUSADA JUNIOR, J.E.; COSTA, J.M.C.; NEIVA, J.N.M.; RODRIGUEZ, N.M. Caracterização físico-química de subprodutos obtidos do processamento de frutas tropicais visando seu aproveitamento na alimentação animal. Rev. Ciênc. Agron., v.37, p.70-76, 2006.

MOLIST, F.; GOMES, S.A.; GASA, A. et al. Effects of the insoluble and soluble dietary fiber on the physicochemical properties of digesta and microbial activity in early weaned piglets. Anim. Feed Sci. Technol., v.149, p.346-353, 2009.

MOREIRA, I.; VOORSLUYS, T.; MARTINS, R.M. et al. Efeitos da restrição energética para suínos na fase final de terminação sobre o desempenho, característica de carcaça e poluição ambiental. Acta Sci. Anim. Sci., v.29, p.179-185, 2007.

PASCOAL, L.A.F.; THOMAZ, M.C.; WATANABE, P.H. et al. Fiber sources in diets for newly weaned piglets. Rev. Bras. Zootec., v.41, p.636-642, 2012.

ROGÉRIO, M.C.P.; BORGES, I.; NEIVA, J.N.M. et al. Valor nutritivo do farelo da indústria processadora de abacaxi (Ananascomosus L.) em dietas para ovinos. Arq. Bras. Med. Vet. Zootec., v.59, p.773-781, 2007.

ROSTAGNO, H.S.; ALBINO, L.F.T.; DONZELE, J.L. et al. Tabelas brasileiras para aves e suíno: composição de alimentos e exigências nutricionais. 3.ed. Viçosa: UFV, 2011. 252p.
SANTOS, T.M.B. Balanço energético $e$ adequação do uso de biodigestores em galpões de frangos de corte. 2001. 167f. Tese (Doutorado em Produção Animal) - Faculdade de Ciências Agrárias e Veterinárias, Universidade Estadual Paulista, Jaboticabal, SP.

SCHIAVON， S.; TAGLIAPIETRA， F.; BAILONI, L.; BORTOLOZZO, A. Effects of sugar beet pulp on growth and health status of weaned piglets. Ital. J. Anim. Sci., v.3, p.337351, 2004.

SMITS, C.H.M.; ANNISON, G. Non starch plant polysaccharides in broiler nutrition towards a physiology valid approach to their determination. World Poult. Sci. J., v.52, p.203-221, 1996.

STATISTICAL analysis system. Version 9.2. Cary: SAS, 2008.

VALADARES FILHO, S.C.; MACHADO, P.A.S.; CHIZZOTTI, M.L. et al. Tabelas brasileiras de composição de alimentos para bovinos: CQBAL 3.0. 2014. Disponível em: $<$ www.ufv.br/cqbal $>$. Acessado em: 23 jan. 2015.

VAN KEULEN, J.; YOUNG, B.A. Evaluation of acid-insoluble ash as natural marker in ruminant digestibility studies. J. Anim. Sci., v.44, p.282287, 1977.

VASCONCELOS, T.S.; RUIZ, U.S.; THOMAZ, M.C. et al. Avaliação biológica do farelo de abacaxi para suínos em terminação. In: CONGRESSO LATINO-AMERICANO DE NUTRIÇÃO ANIMAL, 4., 2014, São Pedro. Anais... São Pedro: CLANA, 2014.

WILLIAMS, B.A.; VERSTEGEN, M.W.A.; TAMMINGA, S. Fermentation in the large intestine of single-stomached animals and its relationship to animal health. Nutr. Res. Rev. v.14, p.207-227, 2001. 